\title{
CORRECTION
}

\section{Correction to: Model of Mercury Flux Associated with Volcanic Activity}

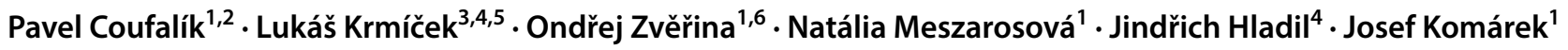

Published online: 4 October 2018

(c) Springer Science+Business Media, LLC, part of Springer Nature 2018

\section{Correction to:}

Bulletin of Environmental Contamination and Toxicology https://doi.org/10.1007/s00128-018-2430-5

The original version of this article contained a mistake in Fig. 2. The country names have been missed in the figure legend along with the $\mathrm{X}$-axis. The corrected figure is given below.

The original article has been corrected.

The original article can be found online at https://doi.org/10.1007/ s00128-018-2430-5.

Lukáš Krmíček

lukas.krmicek@gmail.com

1 Department of Chemistry, Faculty of Science, Masaryk University, Kotlářská 2, 61137 Brno, Czech Republic

2 Institute of Analytical Chemistry of the Czech Academy of Sciences, Veveři 97, 60200 Brno, Czech Republic

3 Faculty of Civil Engineering, Brno University of Technology, Veveří 95, 60200 Brno, Czech Republic

4 Institute of Geology of the Czech Academy of Sciences, Rozvojová 269, 16500 Prague 6, Czech Republic

5 Department of Geological Sciences, Faculty of Science, Masaryk University, Kotlářská 2, 61137 Brno,

Czech Republic

6 Department of Public Health, Faculty of Medicine, Masaryk University, Kamenice 5, 62500 Brno, Czech Republic 


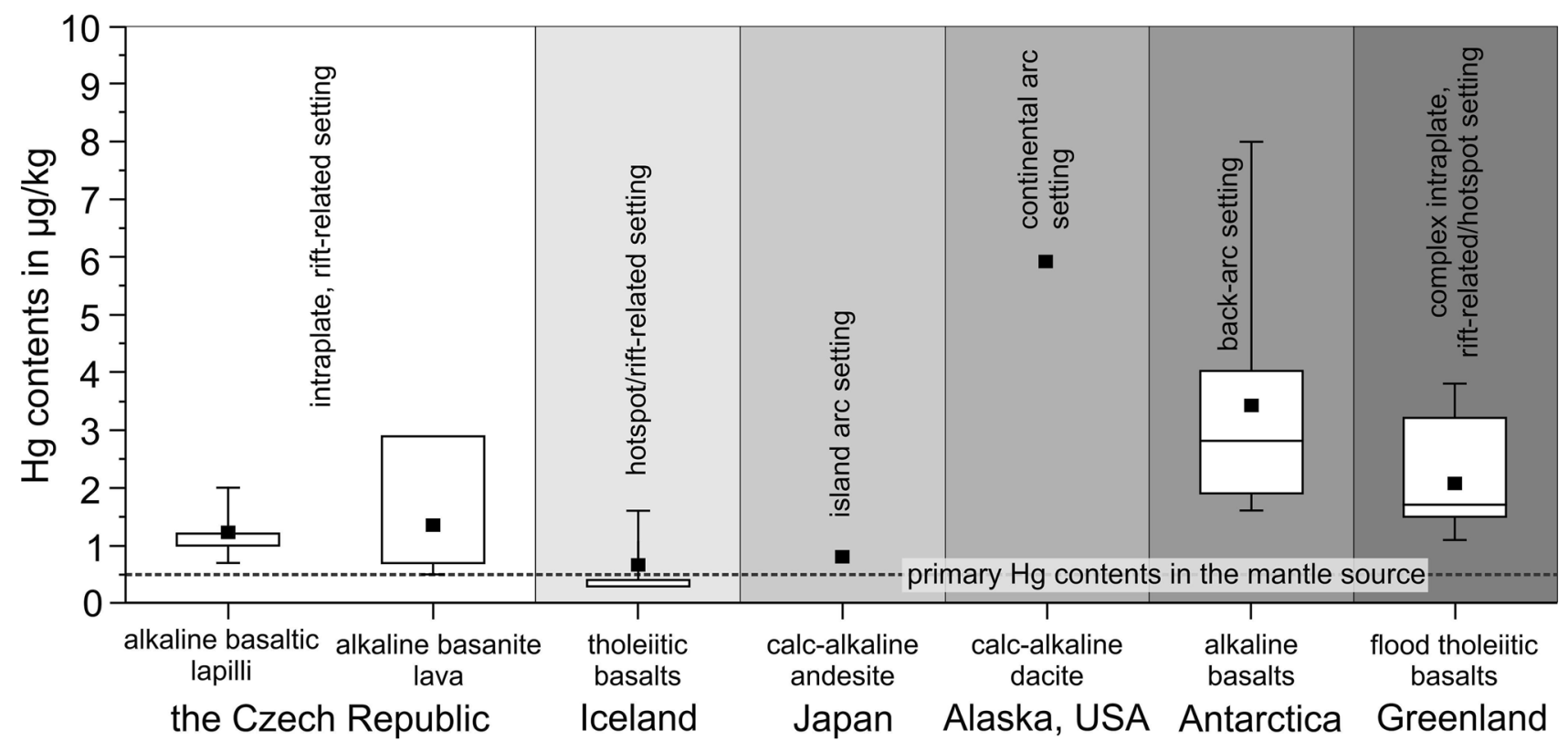

Fig. $2 \mathrm{Hg}$ contents in volcanic rocks from different geotectonic settings. Data for Antarctica and Greenland were taken from Coufalík et al. (2015) 